\title{
An integrated MCDM approach to green supplier selection
}

\author{
Morteza Yazdani*
}

Department of Business Management, Faculty of Social Science, Universidad Europea de Madrid, C/Tajo, Villaviciosa de Odón, 28670, Madrid, Spain

\begin{tabular}{l}
\hline C H R O N I C L E \\
\hline Article history: \\
Received December 22013 \\
Received in Revised Format \\
Mach 172014 \\
Accepted March 202014 \\
Available online \\
March 272014 \\
\hline Keywords: \\
Supplier selection \\
Environmental factors \\
MCDM \\
AHP \\
Fuzzy TOPSIS
\end{tabular}

\section{A B S T R A C T}

\begin{abstract}
Supplier selection management has been considered as an important subject for industrial organizations. In order to remain on the market, to gain profitability and to retain competitive advantage, business units need to establish an integrated and structured supplier selection system. In addition, environmental protection problems have been big solicitudes for organizations to consider green approach in supplier selection problem. However, finding proper suppliers involves several variables and it is critically a complex process. In this paper, the main attention is focused on finding the right supplier based on fuzzy multi criteria decision making (MCDM) process. The weights of criteria are calculated by analytical hierarchical process (AHP) and the final ranking is achieved by fuzzy technique for order preference by similarity to an ideal solution (TOPSIS). TOPSIS advantage among the other similar methods is to obtain the best solution close to ideal solution. The paper attempts to express better understanding by an example of an automobile manufacturing supply chain.
\end{abstract}

\section{Introduction}

In a competitive environment of market, end users require the products with cheaper prices, high quality and on time services. In addition, companies should operate based on consumers' needs and their attitudes. Therefore, they have to reduce their costs, increase their flexibility and keep logical level of quality and services. To improve the quality of products, services and to control total cost of products, several studies have focused on suppliers' evaluation and selection (Awasthi et al., 2010; Che et al., 2010). In supply chain management, supplier selection and evaluation is associated with one of the main strategic practices among overall targets of a company. Strategically, to achieve long-term objectives and to improve efficiency of supply chain, identifying and selecting reliable suppliers would be an important activity ( $\mathrm{Li} \&$ Zhao, 2009). In such situations that the companies have to work with different suppliers to detect appropriate suppliers and to improve the efficiency of supply chain, the purchasing decision and management play crucial role in running good supply program (Fazlollahtabar et al., 2011). Thus, supplier selection and evaluation as a main activity in purchasing department should be supported and mapped.

* Corresponding author. Tel: +34911761239

E-mail: 21256398@live.uem.es (M. Yazdani)

(C) 2014 Growing Science Ltd. All rights reserved. doi: $10.5267 /$ j.jijiec.2014.3.003 
Recently, increasing environment awareness and protection have been concerned to public. Although, information flows, investments and processes might handle a supply chain management properly, due to high awareness among the people and setting legislation, enterprises cannot ignore the role of environmental subjects if they want to remain in the market. In this situation, considering environmental subjects associated with supply chain helps the firms achieve better profit and competitiveness (Kannan et al., 2013). Thus, companies and their purchasing management need to select suppliers with green/environment components to act based on government legislation, to manufacture environmentally and to protect the environment. These reasons accompanying reduction of time to respond to market demand, control cost of green products, quality improvement, better human resource management and decreasing materials with low environmental performance have forced companies to establish and follow an environmental supplier selection problem (Che et al., 2010; Büyüközkan \& Çif̧çi, 2012a).

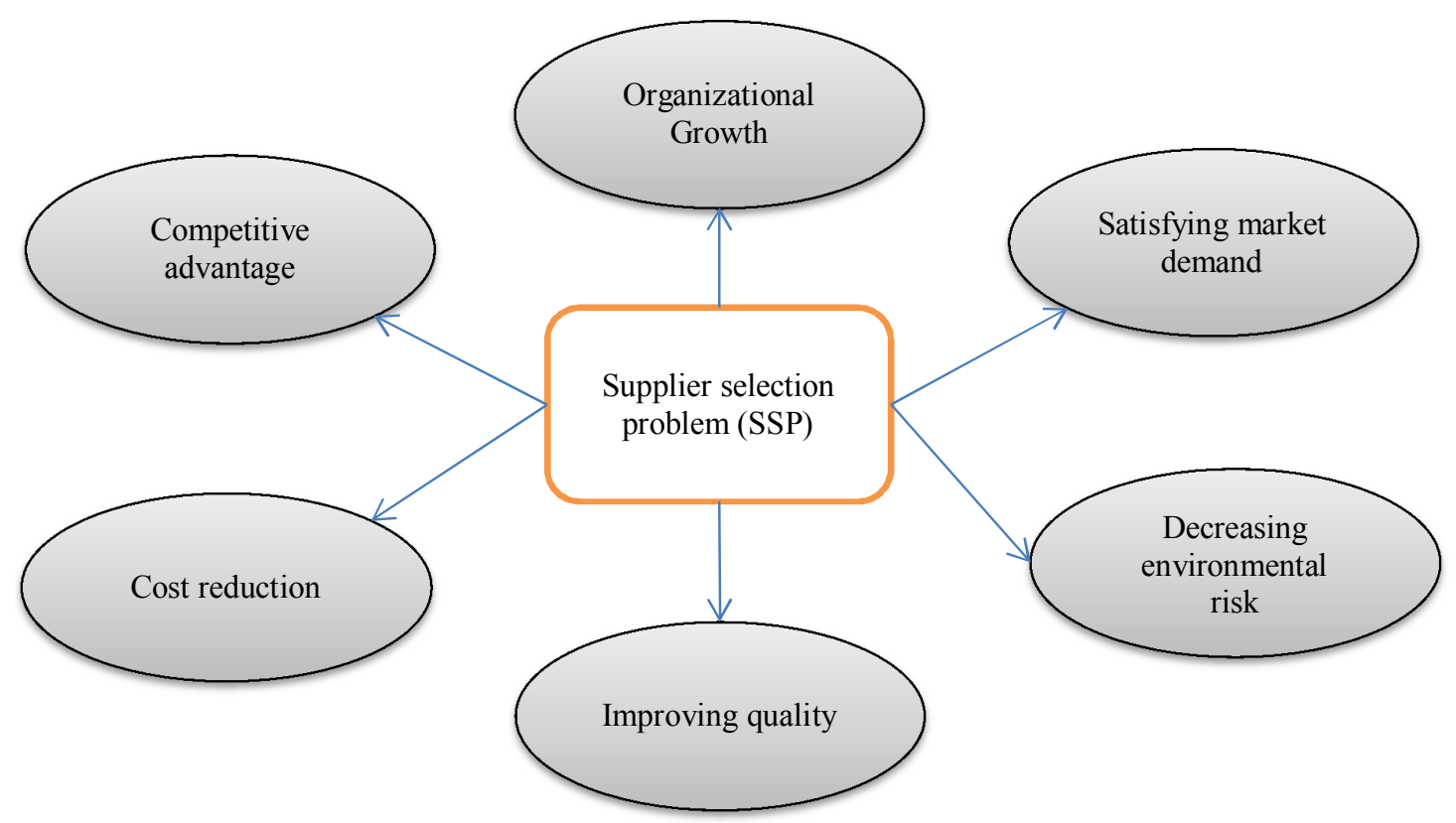

Fig. 1. Supplier selection problem and its general objectives

As mentioned, the supplier selection problem (SSP) is one of the main problems in supply chain management. In Fig. 1, the most related objectives of a supplier selection problem have been illustrated. Generally, a company can reach these objectives by designing, implementing and developing an integrated supplier selection problem considering environmental issues. It seems companies' survival and growth intensively is associated with this subject. However, the process of selecting a group of suppliers, which can potentially influence the company's competitive advantage, is complex and should be based on multiple criteria. Therefore, SSP might include several and different types of criteria and decision models with individuals and variety forms of uncertainty that makes it difficult to handle. Thus, the research is to develop a suitable structure. All in all, SSP involves two main tasks such as, determination of criteria to be used and the method to be applied to compare suppliers (Fazlollahtabar et al., 2011). For this, the current paper will initially investigate and concentrate these tasks.

SSP is a problem of decision making process with multi criteria, which includes tangible, intangible and also qualitative and quantitative criteria. Recognition and determination of factors and criteria under environmental concern is the primal task (Objective) of this study. Several studies investigated factors and criteria in supplier selection problem. The criteria that companies may consider during suppliers selection include; process and product technologies, quality, cost, reliability, capacity, 
service and location (Wisner, 2012). To choose the criteria for supplier selection, the following factors must be considered as; the size of the buyer organization, the preferred sourcing of strategy, supplier capacity, order quantity, geographic preference and the type of product or service purchased (Kuo et al., 2010). In addition, for the process of decision making, the decision team has to determine the weights of criteria. In addition, the form of weighting criteria is critical issue in this part and usually researchers use some different scales of weighting.

Another task in SSP is the method to compare suppliers under determined criteria. In the literature, there are different mathematical methods and techniques for selection of suppliers and most of them are application of multi criteria decision making, as analytical hierarchy process (AHP), fuzzy AHP, data envelopment analysis (DEA), case-based reasoning, decision making trial evaluation laboratory (DEMATEL), analytic network process (ANP), Delphi technique and TOPSIS (Büyüközkan \& Çifçi, 2012b; Awasthi et al., 2010; Humphreys et al., 2003; Lee et al., 2009; Peng, 2012). Although, there are several studies on these methods, the integration of these methods could be stimulated by many authors that increase the merit of research. Several studies have combined following methods to increase the value of the work. However, this study proposes AHP as a comparative model to calculate the weights of criteria and fuzzy TOPSIS for evaluation of the alternative suppliers, which are explained in definitions and models section through illustrated framework.

To prove the integrated model and to find solution for the problem of supplier selection in fuzzy environment, current research proposes a manufacturing company that provides some main parts of an automobile for a car manufacturer and tends to choose the most appropriate suppliers. To do that, the organization of paper is followed here. In section 2, literature survey of supplier selection management and environmental issues associated with SSP are interpreted. Section 3 presents the basic definitions and models such as multi criteria decision making and its applications. AHP, fuzzy approach and TOPSIS model are discussed in this section. Afterwards, the integrated framework of supplier selection is explained as section 4. To show the results, efficiency and validity of the proposed model in section 5 , a numerical example in automotive industry is designed. Finally, section 6 expresses the conclusion and future implications.

\section{Supplier selection review}

Supply chain management (SCM) is the extension of a network of components interrelated together to reach organizational goal, prepare and distribute products and provide services after production. Basically, supply chains are connected together to make value-added approach (Wisner, 2012). Among organizational practices and approaches, there are many new ideas and approaches that supplier selection management is one of those well-known approaches merged and quickly developed across all industries like automotive section (Wen \& Chi, 2010). As can be seen, supplier selection increasingly has been a critical decision in industrial organizations. The decision about supplier selection involves the crucial first step of production and logistics management for firms, because it has a final influence on the competitiveness of the entire supply chain (Razmi et al., 2009). Finally, the purpose of supplier selection is to determine the optimal supplier who can offer the most appropriate products or services, and, in other words, become part of organization supply chain (Songhori et al., 2011). Academic studies have interpreted the green supplier selection subject using various models and approaches. Extending existing models like TOPSIS and AHP, combining techniques and comparing structures just are included small parts of supplier evaluation and selection research areas. Büyüközkan \& Çifçi (2012a, 2012b) supposed hybrid models of fuzzy DEMATEL, fuzzy ANP and fuzzy TOPSIS. Another research to select green suppliers was accomplished by integration of artificial neural network (ANN), DEA and ANP (Kuo, 2010). In addition, fuzzy ANP and fuzzy PROMETHEE were deployed to evaluate the environmental performance of suppliers where ANP was used for interrelationship among criteria and PROMETHEE to reach an outranking solution (Tuzkaya et al., 2009). In other research project, Awasthi et al. (2011) evaluated environmental performance of suppliers using fuzzy TOPSIS and sorts of factors as; green technology, environmental management systems, personnel education and design for environment. Moreover, integration of fuzzy TOPSIS and multi-objective linear 
programming (MOLP) have been lead to a supplier selection and order allocation problem in a green supply chain management system (Kannan et al., 2013). Further paragraphs is devoted the research on environmental factors review and finding the most appropriate ones.

\section{Definitions and models}

\subsection{The AHP method}

The nature of MCDM is to make a precise preference for decision makers and to reduce the risk of decision making. Therefore, a decision process needs to be supported by an exact and low risk method with high effectiveness. In addition, each problem can be assessed independently and easily by disintegrating the decision problem into a hierarchy that increases efficacy and reduce probable errors. AHP, proposed by Saaty (1980) and Amiri (2010), is a multiple criteria decision making tool that addresses how to determine the relative importance of a set of activities in a multi criteria decision problem and normally is applied to overcome problems in uncertain condition. When applying AHP, incorporating judgments on tangible and intangible criteria and determining the weights of each criterion are the ways AHP proposes to find pair wise comparison matrix (Badri, 2001). Actually, the most considerable advantage of AHP is the hierarchy structure of the model it considers and thereby, the element of hierarchy in AHP method can relate to any application of decision making problem which needs individual to choose among potential alternatives and search for the weight of evaluation index (Wu et al., 2012; Khajeh, 2010). The first step in AHP is making some levels of hierarchy of interrelated decision criteria and alternatives regarding problem objectives. The next step includes comparing the alternatives and criteria by prioritizing in order to determine the relative importance of criteria in each level of hierarchy (Amiri, 2010). Therefore, it can be inferred that AHP as a reliable function helps this study for these tasks; obtaining weights of criteria, making decision hierarchy, pulling down decision risk and increasing effectiveness of the problem.

AHP in recent decades has been increasingly applied to solve many kinds of multi criteria decision problems. Some scholars have found AHP as an effective rule in varieties of problems including effects of environmental and climate changes (Berrittella et al., 2007), university faculty selection (Grandzol, 2005), university ranking (Wu et al., 2012) and financial decisions making (Meziani \& Rezvani, 1990). In a study on ranking e-commerce websites in an e-alliance, AHP was used to analyze the structure of problem and to calculate the weights of criteria (Yu et al., 2011). Khorramshahgol (2012) and Fu and Lin (2009) similarly used AHP as an instrument to measure the relative weights of criteria in a supplier selection problem and performance measurement of national energy promotion project, respectively. AHP stepwise procedure to carry out the relative importance of criteria is represented here. AHP methodology follows the steps below to find relative importance degree of criteria:

Step 1 - Prepare the pair wise comparison matrix A by utilizing the ratio scale in Table 1.

\section{Table 1}

The ratio scale and definition of AHP

\begin{tabular}{cl}
\hline Intensity of importance & Definition \\
\hline 1 & Equally important \\
3 & Moderately important \\
5 & Strongly more important \\
7 & Very strong important \\
9 & Extremely more important \\
$2,4,6,8$ & Intermediate more important \\
\hline
\end{tabular}

Saaty (1980)

Step 2 - Let $C_{1}, C_{2}, \ldots . ., C_{n}$ be the set of elements, although $a_{i j}$ presents a quantified judgment on pair of elements $C_{i .}, C_{j}$, the matrix A as below; 


$$
A=\left[a_{i j}\right]=\left[\begin{array}{cccc}
1 & a_{12} & \ldots & a_{1 n} \\
\frac{1}{a_{12}} & 1 & \ldots & a_{2 n} \\
\vdots & \vdots & \vdots & \vdots \\
\frac{1}{a_{1 n}} & \frac{1}{a_{2 n}} & \ldots & 1
\end{array}\right]
$$

where, $a_{i j}=1$ and $a_{j i}=\frac{1}{a_{i j}}, i . j=1,2, \ldots, n$

In matrix $\mathrm{A}$, the problem is on determining a set of numerical weights $W_{1}, W_{2}, \ldots ., W_{n}$ in front of $n$ element $C_{1}, C_{2}, \ldots ., C_{n}$. If $A$ is a consistency matrix, then the relation between weights and judgments are given by $a_{i j}=\frac{W_{j}}{W_{i}}$, for $(i, j=1,2,3, \ldots, n)$. The largest Eigen-value $\lambda_{\max }$ would be suggested by Saaty (1980) as;

$\lambda_{\max }=\sum_{j=1}^{n} a_{i j} \frac{W_{j}}{W_{i}}$

Let $A$ be the consistency matrix, then eigenvector $X$ can be computed as follows,

$$
\left(A-\lambda_{\max } I\right) X=0
$$

So, the consistency index (C.I.) and random index (R.I.) verify the consistency ratio (C.R.). The consistency index and consistency rate are as indicated;

$$
\text { C.I. }=\frac{\lambda_{\max }-n}{n-1} \text {, and C.R. }=\frac{C . I}{R . I}
$$

The number 0.1 is the accepted upper limit of C.R. If the final consistency ration is higher this value, the evaluation process should be done again to improve consistency.

\subsection{Preliminary of fuzzy approach}

Fuzzy set theory is a class of objects with grades of membership applied to model vagueness and handle uncertainty by a membership function, which is between zero and one (Zadeh, 1965; Kutlu \& Ekmekçioğlu, 2012). It utilizes linguistic terms to present decision makers preferences. This study applies fuzzy linguistics variables to model supplier selection problem since experts judgments usually cannot be detected clearly. In supplier selection problem some definitions of criteria like quality of services and capability of suppliers might be delivered by fuzzy set theory. In the literature, since decades ago authors have referred and cited fuzzy logic which this paper explains some basic definitions as follows (Zadeh, 1965; Buckley, 1985; Kaufman \& Gupta, 1985; Zimmermann, 1992; Chen, 2000; Yang \& Hung, 2007);

Definition 1 - A fuzzy set $\tilde{A}$ in a universe of discourse $X$ is described by membership function $\mu_{-}(x)$. It connects with each element $x$ in $X$, a real number in the interval[0,1]. The function value $\mu_{-}(x)$ is designated the grade of membership of $x$ in $\tilde{A}$.

This study focuses on triangular fuzzy numbers. A triangular fuzzy number $\tilde{\mathrm{A}}$ is defined by $\left(a_{1}, a_{2}, a_{3}\right)$, where $a_{3}>a_{2}>a_{1}$. The following equation displays mathematical form of triangular fuzzy number and Fig. 2 also represents a triangular number. 
$\mu_{a}(x)=\left\{\begin{array}{cc}0, & x \leq a_{1} \\ \frac{x-a_{1}}{a_{2}-a_{1}}, & a_{1}<x \leq a_{2} \\ \frac{a_{3}-x}{a_{3}-a_{2}}, & a_{2}<x \leq a_{3} \\ 0, & x>a_{3}\end{array}\right.$

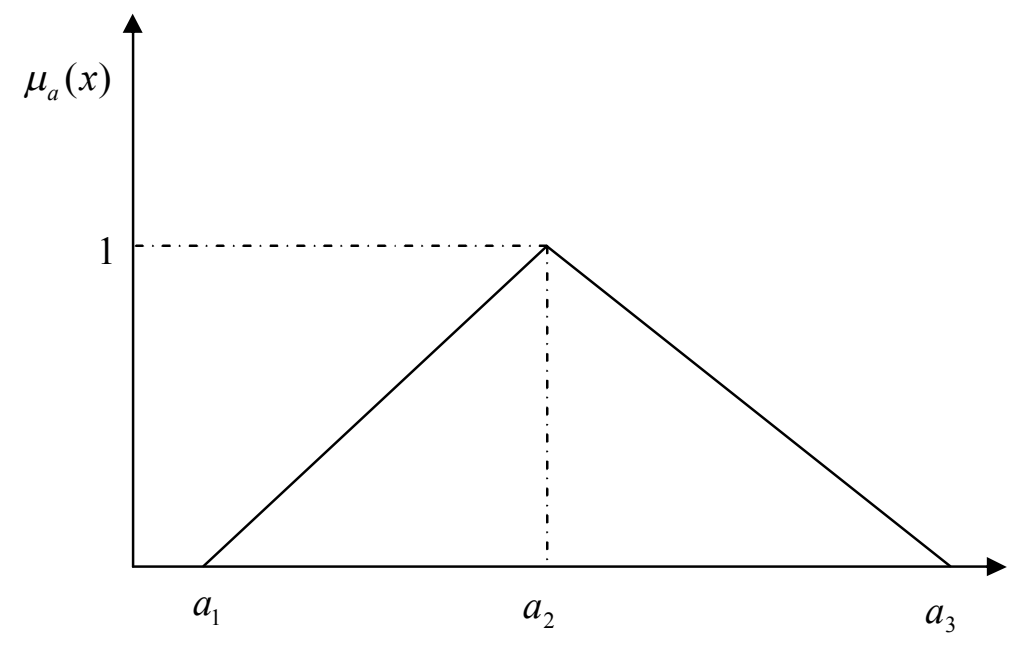

Fig. 2. Triangular number

Definition 2 - Let $a=\left(a_{1}, a_{2}, a_{3}\right)$ and $b=\left(b_{1}, b_{2}, b_{3}\right)$ be two triangular fuzzy numbers, the distance between them is computed as Eq. (5) as follows,

$$
d \tilde{a}, \tilde{b})=\sqrt{\frac{1}{3}\left[\left(a_{1}-b_{1}\right)^{2}+\left(a_{2}-b_{2}\right)^{2}+\left(a_{3}-b_{3}\right)^{2}\right]}
$$

In addition, the Table 2 shows the operational equations of the two triangular fuzzy numbers.

\section{Table 2}

Basic equations of the two triangular fuzzy numbers

\begin{tabular}{ll}
\hline Operational law & Equations \\
\hline Addition & $(a+b)=\left(a_{1}+b_{1}, a_{2}+b_{2}, a_{3}+b_{3}\right)$ \\
Subtraction & $(a-b)=\left(a_{1}-b_{1}, a_{2}-b_{2}, a_{3}-b_{3}\right)$ \\
Multiplication & $(a \times b)=\left(a_{1} \times b_{1}, a_{2} \times b_{2}, a_{3} \times b_{3}\right), k(a)=\left(k a_{1}, k a_{2}, k a_{3}\right)$ \\
Division & $(a \div b)=\left(a_{1} \div b_{1}, a_{2} \div b_{2}, a_{3} \div b_{3}\right)$ \\
Inverse & $\left(a_{1}, a_{2}, a_{3}\right)^{-1}=\left(\frac{1}{a_{3}}, \frac{1}{a_{2}}, \frac{1}{a_{1}}\right)$ \\
\hline
\end{tabular}

\subsection{The fuzzy TOPSIS method}

TOPSIS approach as one of the most applied and practical techniques in classical multiple criteria decision making methods was proposed by Hwang and Yoon (1981) to analyze alternative solutions among each criterion and ultimately to determine the most efficient alternatives. The TOPSIS algorithm originates from having the shortest distance from the positive ideal solution (PIS) and farthest from negative ideal solution (NIS). However, often for decision makers somehow it would be severe to assign a precise evaluation rating to an alternative. The advantage of using fuzzy approach in 
this study is to overcome the vagueness of human judgments and to get relative importance of attributes (Yang \& Hung, 2007). The fuzzy TOPSIS comes to distinguish fuzzy evaluation of alternatives among criteria in traditional TOPSIS (Awasthi et al., 2010; Wang et al., 2009). Supplier selection in this study develops TOPSIS to a group decision process, which has been provided by Chen (2000). This proposed approach uses linguistic variables, which can be converted to fuzzy numbers easily. Now, the fuzzy TOPSIS procedure is introduced here (Awasthi et al., 2011);

Step 1 - Assignment of rating to criteria and alternatives. Suppose there are $j$ possible candidates called $A=\left\{A_{1}, A_{2}, \ldots . . A_{j}\right\}$, which are evaluated against $m$ criteria, $C=\left\{C_{1}, C_{2}, \ldots . . C_{m}\right\}$. The criteria weights are described by $w_{i}=\{i=1,2, \ldots . ., m\}$. The performance ratings of each decision maker $D_{k}(k=1,2, \ldots ., K)$ for each alternative $A_{j}(j=1,2, \ldots ., n)$ respecting to criteria $C_{i}(i=1,2, \ldots, m)$ are determined by $\tilde{R}_{k}=\tilde{x}_{i j k}(i=1,2, \ldots, m ; j=1,2, \ldots ., n ; k=1,2, \ldots ., k)$ with membership function $\mu_{\tilde{R}_{k}}(x)$

Step 2 - Calculate aggregate fuzzy rating for the alternatives and the criteria. Supposed that the fuzzy rating of all decision maker about criteria are defined as triangular fuzzy numbers $\tilde{R}_{k}=\left(a_{k}, b_{k}, c_{k}\right)$, $k=1,2, \ldots . ., K$, then the aggregated fuzzy rating is given by $\tilde{R}=(a, b, c), k=1,2, \ldots . ., K$, where

$$
a=\min _{k}\left\{a_{k}\right\}, \quad b=\frac{1}{k} \sum_{k=1}^{K} b_{k}, \quad c=\max _{k}\left\{c_{k}\right\} .
$$

If the fuzzy rating and importance weight of the $k^{\text {th }}$ decision maker are $\tilde{x}_{i j k}=\left(a_{i j k}, b_{i j k}, c_{i j k}\right)$ and $\tilde{w}_{i j k}=\left(w_{j k 1}, w_{j k 2}, w_{j k 3}\right), i=1,2, \ldots, m, j=1,2, \ldots . ., n$ respectively, then the integrated fuzzy ratings $\left(\tilde{x}_{i j}\right)$ of alternatives with respect to each criterion are given by $\tilde{x}_{i j}=\left(a_{i j}, b_{i j}, c_{i j}\right)$ where

$$
a_{i j}=\min _{k}\left\{a_{i j k}\right\}, \quad b_{i j}=\frac{1}{k} \sum_{k=1}^{K} b_{i j k}, \quad c_{i j}=\max _{k}\left\{c_{i j k}\right\} .
$$

The aggregated fuzzy weights $\left(\tilde{w}_{i j}\right)$ of each criterion are computed as $\tilde{w}_{j}=\left(w_{j 1}, w_{j 2}, w_{j 3}\right)$ where

$$
w_{j 1}=\min _{k}\left\{w_{1 j k}\right\}, \quad w_{j 2}=\frac{1}{k} \sum_{k=1}^{K} w_{j k 2}, \quad w_{j 3}=\underset{k}{\max \left\{c_{j k 3}\right\}} .
$$

Step 3 - Compute the fuzzy decision matrix

The fuzzy decision matrix for alternatives $(\tilde{D})$ and criteria $(\tilde{W})$ is constructed;

$$
\begin{aligned}
\tilde{D} & =\left[\begin{array}{cccc}
\tilde{x}_{11} & \tilde{x}_{12} & \ldots & \tilde{x}_{1 n} \\
\tilde{x}_{21} & \tilde{x}_{22} & \ldots & \tilde{x}_{2 n} \\
\ldots & \ldots & \ldots & \ldots \\
\tilde{x}_{m 1} & \tilde{x}_{m 1} & \ldots & \tilde{x}_{m n}
\end{array}\right], \quad i=1,2, \ldots ., m, \quad j=1,2, \ldots ., n \\
\tilde{W} & =\left(\tilde{w}_{1}, \ldots ., \tilde{w}_{n}\right) .
\end{aligned}
$$

Step 4 - The raw data are normalized using a linear scale transforming to bring the various criterion scales on to a comparable scale. The normalized fuzzy decision matrix is given by

$$
\tilde{R}=\left[\tilde{r}_{i j}\right]_{m \times n}, \quad i=1,2, \ldots \ldots, m, \quad j=1,2, \ldots \ldots, n,
$$

Where

$$
\tilde{r}_{i j}=\left(\frac{a_{i j}}{c_{j}^{*}}, \frac{b_{i j}}{c_{j}^{*}}, \frac{c_{i j}}{c_{j}^{*}}\right) \text {, and } \quad c_{j}^{*}=\max _{i} c_{i j} \text { (benefit criteria) }
$$




$$
\tilde{r}_{i j}=\left(\frac{a_{j}^{-}}{c_{i j}}, \frac{a_{j}^{-}}{b_{i j}}, \frac{a_{j}^{-}}{a_{i j}}\right) \text {, and } \quad a_{j}^{-}=\min _{i} a_{i j} \text { (cost criteria) }
$$

Step 5 - Calculation of weighted normalized matrix. The weighted normalized matrix $\tilde{V}$ for criteria is calculated by multiplication of the weights $\left(\tilde{w}_{j}\right)$ of evaluation criteria with the normalized fuzzy decision matrix $\tilde{r}_{i j}$;

$$
\tilde{v}=\left[\tilde{v}_{i j}\right]_{m \times n}, \quad i=1,2, \ldots . m, \quad j=1,2, \ldots \ldots, n
$$

Where

$$
\tilde{v}_{i j}=\tilde{r}_{i j}(.) \tilde{w}_{j} .
$$

Step 6 - Calculation of the FPIS (fuzzy positive ideal solution) and FNIS (fuzzy negative ideal solution) for alternatives. FPIS and FNIS are computed as follows;

$$
A^{*}=\left(\tilde{v}_{1}^{*}, \cdots, \tilde{v}_{n}^{*}\right),
$$

where

$$
\begin{aligned}
& \tilde{v}_{j}^{*}=\max _{i}\left\{v_{i j 3}\right\}, i=1,2, \ldots ., m \text { and } j=1,2, \ldots, n \\
& A^{*}=\left(\tilde{v}_{1}^{-}, \cdots, \tilde{v}_{n}^{-}\right),
\end{aligned}
$$

where

$$
\tilde{v}_{j}^{-}=\min _{i}\left\{v_{i j 1}\right\}, i=1,2, \ldots, m \text { and } j=1,2, \ldots, n
$$

Step7 - compute the distance of each alternative from FPIS and FNIS. The distance $\left(d_{i}^{*}, d_{i}^{-}\right)$of each weighted alternative $i=1,2, \ldots ., m$ from the FPIS and FNIS is presented here;

$$
\begin{array}{ll}
d_{i}^{*}=\sum_{j=1}^{n} d_{v}\left(\tilde{v}_{i j}, \tilde{v}_{j}^{-}\right), & i=1,2, \ldots ., m \\
d_{i}^{-}=\sum_{j=1}^{n} d_{v}\left(\tilde{v}_{i j}, \tilde{v}_{i j}^{-}\right), & i=1,2, \ldots, m
\end{array}
$$

Where $d_{v}(\tilde{a}, \tilde{b})$ is the distance measurement between two fuzzy numbers $\tilde{a}$ and $\tilde{b}$

Step 8 - Compute the closeness coefficient $\left(c c_{i}\right)$ of each alternative. The closeness coefficient represents the distances to the fuzzy positive ideal solution and fuzzy negative ideal solution simultaneously. The closeness coefficient of each alternative is calculated by;

$$
c c_{i}=\frac{d_{i}^{-}}{d_{i}^{-}+d_{i}^{*}}, \quad i=1,2, \ldots ., m
$$

Step 9 - Rank the alternatives

\section{Proposed framework of green supplier selection}

The model designs a three phase's decision model that has been illustrated by Fig. 3 . 


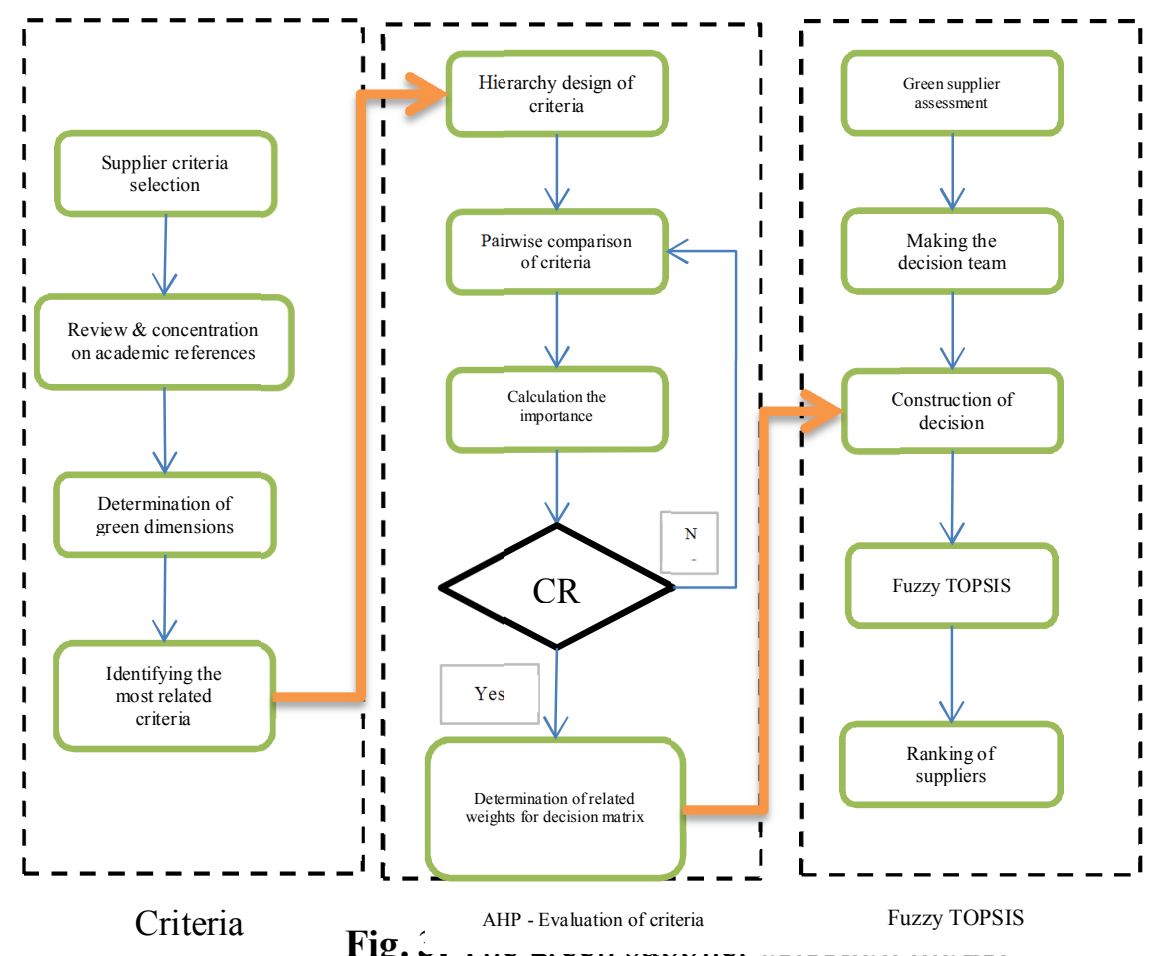

In the first phase, the research experts determine the related dimensions and criteria. This process is accomplished by reviewing and studying of related papers and books to obtain the most useful ones. By identifying the right and appropriate criteria, the study can assure that the supplier selection process will be more accurate and reliable; therefore, the decision hierarchy is formed. As described, AHP divides the decision model into a hierarchy as shown in Fig. 4. The next phase, as the second, is indicated and represented AHP computations. There are different kinds of methods which evaluate the suppliers' performance, but the study proposes the applicable and strategic method to calculate the final ranking of suppliers. This phase is the third step and the alternatives are evaluated using fuzzy TOPSIS and linguistic variables (see Table 3). Briefly, the proposed framework of environmental supplier selection consists of three phases, which are illustrated in Fig. 3;

1. Selection of supplier evaluation criteria

2. Evaluation and determination of the weights of criteria

3. Evaluation and selection of best alternatives among the selected criteria

The supplier selection in a manufacturing system is a vital task to be deployed because the origin of production process begins by suppliers and their performances. Providing the best fitted raw material, technical requirements up to packaging and distribution systems will make a production process as reliable as. The paper includes a small manufacturing company that delivers some parts of a new automobile in Iran. The management concern has focused on assessment and selection of material suppliers regarding environmental issues. So the problem defines a decision making process with different criteria and potential suppliers. Decision team presents performance rating of suppliers in order to establish a suitable matrix. In addition, the fuzzy approach helps the team to express better rate for supplies. Table 3 describes further, and considers fuzzy numbers used along with their definitions. 


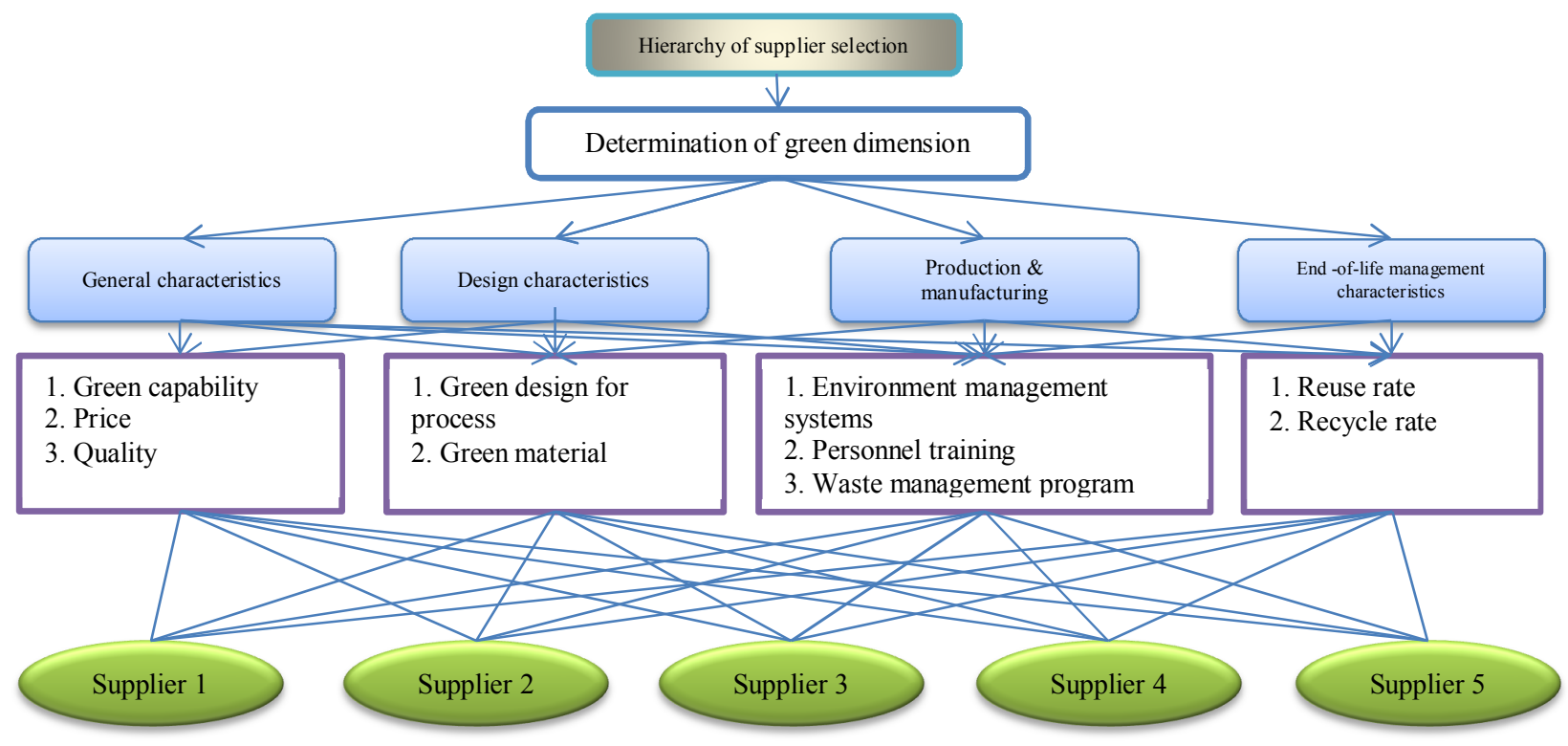

Fig. 4. Hierarchical view of green supplier selection criteria

Table 3

Linguistic values and fuzzy numbers

\begin{tabular}{ll}
\hline Linguistic variables & Fuzzy numbers \\
\hline Very poor (VP) & $(1,1,3)$ \\
Poor (P) & $(1,3,5)$ \\
Fair (F) & $(3,5,7)$ \\
Good (G) & $(5,7,9)$ \\
Very good (VG) & $(7,9,9)$ \\
\hline
\end{tabular}

\subsection{Introductory set of supplier evaluation criteria}

The study establishes the list of related criteria involving two main components. Initially, a literature survey was conducted by author to collect criteria from most cited and top academic publications. Second, we have gathered relevant set of supplier selection criteria by performing several interviews with purchasing experts. Based on the literature review and regarding academic articles and research projects published in purchasing and supplier selection management journals, more than 40 articles were found. In addition, by interview with managers and professionals in this field, the study has done categories and groups to picture view of criteria. Wong et al. (2012) worked on environmental supplier criteria and classified the criteria into three groups like; general criteria, corporate social responsibility related criteria and environmental responsibility relevant criteria. Similar categories also have been accomplished by other authors. For example, Büyüközkan \& Çifçi (2012a) supposed these three dimensions for a green supplier selection problem; organizational performance dimensions, green logistic dimensions, green organizational activities dimensions and acquired these criteria to qualify and to rank suppliers; organization, financial performance, service quality, technology and green competencies. To optimize the process of supplier selection, Peng (2012), utilized a green supplier evaluation index system that established four layers as; enterprise ability, service level, cooperation degree, environmental factors. Briefly, the most used criteria based on academic and international publication are included; environmental management system (Humphreys et al., 2006; Li \& Zhao, 2009; Yan, 2009; Zhang et al., 2003; Kuo et al., 2010; Lee et 1., 2009; Chen, 2010; Grisi, 2010; Chiou, 2008), quality (Kuo et al., 2010; Lee, 2009; Yang and Wu, 2008; Li \& Zhao, 2009; Yan, 2009; Grisi, 
2010; Zhang, 2003; Wen, 2010), service (Kuo et al., 2010; Yang \& Wu, 2008; Wen \& Chi, 2010; Li \& Zhao, 2009; Bala et al., 2008; Yan, 2009), technology (Büyüközkan \& Çifçi, 2012b; Li \& Zhao, 2009; Lee, 2009; Wen, 2010), green image (Lee et al., 2009; Humphreys et al., 2006; Humphreys et al., 2003; Grisi et al., 2010), green competency (Lee et al., 2009; Noci, 1997; Chiou, 2008), and price (Yang \& Wu, 2008; Grisi, et al., 2010; Yan, 2009).

Table 4

Criteria and definitions

\begin{tabular}{|c|c|c|}
\hline Criteria & Criterion & Definition \\
\hline $\mathrm{C}_{1}$ & Green capability & $\begin{array}{l}\text { The ability to prepare, produce and deliver green products based on } \\
\text { environmental standards }\end{array}$ \\
\hline $\mathrm{C}_{2}$ & Price & The total cost of products offered as the price \\
\hline $\mathrm{C}_{3}$ & Quality & The ability to meet quality specification consistently \\
\hline $\mathrm{C}_{4}$ & Green design & $\begin{array}{l}\text { A systematic method to reduce the environmental impact of products and } \\
\text { processes }\end{array}$ \\
\hline $\mathrm{C}_{5}$ & Green material & $\begin{array}{l}\text { Degree of green and environmental friendly material in production } \\
\text { process }\end{array}$ \\
\hline $\mathrm{C}_{6}$ & Environmental management system & Applying any environmental management systems like ISO 14000 \\
\hline $\mathrm{C}_{7}$ & Personnel training & What is the program of company to educate and train the personnel? \\
\hline $\mathrm{C}_{8}$ & Waste management program & What kind of waste management policy the companies follow? \\
\hline $\mathrm{C}_{9}$ & Re-use rate & $\begin{array}{l}\text { The rate of collecting used products from the field, and distributing or } \\
\text { selling them }\end{array}$ \\
\hline $\mathrm{C}_{10}$ & Re-cycle rate & $\begin{array}{l}\text { The rate of collecting used products, disassembling and separating to } \\
\text { reprocess }\end{array}$ \\
\hline
\end{tabular}

Based on these factors associated with supplier selection problems and the explained contents, the criteria and their definitions used in this paper have been clarified in Table 4 . The study considers the criteria and sub criteria to make a hierarchy. As Fig. 4 shows, there are four man criteria (dimensions) like; general characteristics, design characteristics, production characteristics and end-of-life management characteristics. The sub criteria have been constructed in four boxes and Table 4 represents them and their definitions. The next part will completely demonstrate the process of weight determination of any criteria.

\subsection{AHP approach for weights determination}

After determining the right criteria and sub criteria, their weights need to be computed based on AHP represented in 3.1. AHP model is constructed in three levels as Fig. 4 pictures. In the first level, there are the four dimensions as general characteristics, design characteristics, production characteristics and end-of-life management. In addition, five main suppliers are supposed to being evaluated in a decision making procedure. Table 5 shows the pair wise comparison matrix that the experts have brought it out.

\section{Table 5}

Pair wise comparison matrix of criteria

\begin{tabular}{cccccccccccc}
\hline & $\mathrm{C}_{1}$ & $\mathrm{C}_{2}$ & $\mathrm{C}_{3}$ & $\mathrm{C}_{4}$ & $\mathrm{C}_{5}$ & $\mathrm{C}_{6}$ & $\mathrm{C}_{7}$ & $\mathrm{C}_{8}$ & $\mathrm{C}_{9}$ & $\mathrm{C}_{10}$ \\
\hline $\mathrm{C}_{1}$ & 1.00 & 9.00 & 2.00 & 6.00 & 2.00 & 3.00 & 5.00 & 2.00 & 4.00 & 2.00 \\
$\mathrm{C}_{2}$ & 0.11 & 1.00 & 0.25 & 0.13 & 0.11 & 0.20 & 0.20 & 0.11 & 0.25 & 0.33 \\
$\mathrm{C}_{3}$ & 0.50 & 4.00 & 1.00 & 7.00 & 3.00 & 2.00 & 3.00 & 2.00 & 3.00 & 2.00 \\
$\mathrm{C}_{4}$ & 0.17 & 8.00 & 0.14 & 1.00 & 0.14 & 0.20 & 0.50 & 0.25 & 0.33 & 0.25 \\
$\mathrm{C}_{5}$ & 0.50 & 9.09 & 0.33 & 7.14 & 1.00 & 2.00 & 3.00 & 3.00 & 2.00 & 3.00 \\
$\mathrm{C}_{6}$ & 0.33 & 5.00 & 0.50 & 5.00 & 0.50 & 1.00 & 2.00 & 4.00 & 2.00 & 3.00 \\
$\mathrm{C}_{7}$ & 0.20 & 5.00 & 0.33 & 2.00 & 0.33 & 0.50 & 1.00 & 0.50 & 3.00 & 0.50 \\
$\mathrm{C}_{8}$ & 0.50 & 9.00 & 0.50 & 4.00 & 0.33 & 0.25 & 2.00 & 1.00 & 2.00 & 2.00 \\
$\mathrm{C}_{9}$ & 0.25 & 4.00 & 0.33 & 3.00 & 0.50 & 0.50 & 0.33 & 0.50 & 1.00 & 0.50 \\
$\mathrm{C}_{10}$ & 0.50 & 3.03 & 0.50 & 4.00 & 0.33 & 0.33 & 2.00 & 0.50 & 2.00 & 1.00 \\
\hline
\end{tabular}


The weights of criteria are shown in Table 6. Green capability has the highest importance between others and the weight of price is the smallest ones. As the Table 6 shows, consistency ratio of weights is computed as $0.088<0.1$. Therefore, these weights are appropriate and can be used in the process of selection.

Table 6

\begin{tabular}{cccccc} 
Weights of criteria & \multicolumn{1}{l}{} & & & \\
\hline Criteria & Weights & $\lambda$ & $C J$ & $R J$ & $C . R$ \\
\hline $\mathrm{C}_{1}$ & 0.219 & 11.201 & 0.13 & 1.51 & \\
$\mathrm{C}_{2}$ & 0.018 & & & & \\
$\mathrm{C}_{3}$ & 0.170 & & & \\
$\mathrm{C}_{4}$ & 0.035 & & & \\
$\mathrm{C}_{5}$ & 0.152 & & & \\
$\mathrm{C}_{6}$ & 0.124 & & & \\
$\mathrm{C}_{7}$ & 0.061 & & & \\
$\mathrm{C}_{8}$ & 0.095 & & & \\
$\mathrm{C}_{9}$ & 0.051 & & & \\
$\mathrm{C}_{10}$ & 0.075 & & & \\
\hline
\end{tabular}

\subsection{Supplier evaluation and selection using fuzzy TOPSIS}

The model tends to evaluate suppliers under environmental factors. The initial evaluation according to subjective judgments is expressed by linguistic variables that acquired in this study. The main guideline for evaluators to rate and express their idea about suppliers is included in Table 3. For example when an alternative is acting as proper as the decision maker gives the "good" or "very good" linguistic variable by the related fuzzy numbers as $(5,7,9)$ or $(7,9,9)$ respectively. The rating of each alternatives considering environmental criteria that stated by three decision maker (evaluators) listed in Table 7. As can be seen, the five alternative suppliers among several criteria are arranged based on evaluators' attitudes. The next action is to transform verbal and linguistic variables into fuzzy numbers which the transformed data are shown in Table 8 . In addition the weights of criteria considering the formulation of fuzzy TOPSIS will put down under the fuzzy numbers.

Table 7

Environmental rating of decision makers for alternatives

\begin{tabular}{ccccccccccc}
\hline & $\mathrm{C}_{1}$ & $\mathrm{C}_{2}$ & $\mathrm{C}_{3}$ & $\mathrm{C}_{4}$ & $\mathrm{C}_{5}$ & $\mathrm{C}_{6}$ & $\mathrm{C}_{7}$ & $\mathrm{C}_{8}$ & $\mathrm{C}_{9}$ & $\mathrm{C}_{10}$ \\
\hline $\mathrm{A}_{1}$ & $\mathrm{G}$ & $\mathrm{P}$ & $\mathrm{G}$ & $\mathrm{P}$ & $\mathrm{G}$ & $\mathrm{VG}$ & $\mathrm{F}$ & $\mathrm{G}$ & $\mathrm{G}$ & $\mathrm{G}$ \\
$\mathrm{A}_{2}$ & $\mathrm{G}$ & $\mathrm{F}$ & $\mathrm{G}$ & $\mathrm{VG}$ & $\mathrm{G}$ & $\mathrm{G}$ & $\mathrm{G}$ & $\mathrm{G}$ & $\mathrm{G}$ & $\mathrm{G}$ \\
$\mathrm{A}_{3}$ & $\mathrm{~F}$ & $\mathrm{G}$ & $\mathrm{F}$ & $\mathrm{G}$ & $\mathrm{F}$ & $\mathrm{F}$ & $\mathrm{G}$ & $\mathrm{G}$ & $\mathrm{VG}$ & $\mathrm{G}$ \\
$\mathrm{A}_{4}$ & $\mathrm{VG}$ & $\mathrm{G}$ & $\mathrm{G}$ & $\mathrm{G}$ & $\mathrm{F}$ & $\mathrm{G}$ & $\mathrm{G}$ & $\mathrm{P}$ & $\mathrm{G}$ & $\mathrm{G}$ \\
$\mathrm{A}_{5}$ & $\mathrm{G}$ & $\mathrm{G}$ & $\mathrm{VG}$ & $\mathrm{G}$ & $\mathrm{G}$ & $\mathrm{G}$ & $\mathrm{G}$ & $\mathrm{F}$ & $\mathrm{G}$ & $\mathrm{F}$ \\
\hline
\end{tabular}

Table 8

Fuzzy evaluation matrix and weights of criteria

\begin{tabular}{ccccccccccc}
\hline \multicolumn{1}{c}{$\mathrm{C}_{1}$} & $\mathrm{C}_{2}$ & $\mathrm{C}_{3}$ & $\mathrm{C}_{4}$ & $\mathrm{C}_{5}$ & $\mathrm{C}_{6}$ & $\mathrm{C}_{7}$ & $\mathrm{C}_{8}$ & $\mathrm{C}_{9}$ & $\mathrm{C}_{10}$ \\
\hline $\mathrm{A}_{1}$ & $(5,7,9)$ & $(1,3,5)$ & $(5,7,9)$ & $(1,3,5)$ & $(5,7,9)$ & $(7,9,9)$ & $(3,5,7)$ & $(5,7,9)$ & $(5,7,9)$ & $(5,7,9)$ \\
$\mathrm{A}_{2}$ & $(5,7,9)$ & $(3,5,7)$ & $(5,7,9)$ & $(7,9,9)$ & $(5,7,9)$ & $(5,7,9)$ & $(5,7,9)$ & $(5,7,9)$ & $(5,7,9)$ & $(5,7,9)$ \\
$\mathrm{A}_{3}$ & $(3,5,7)$ & $(5,7,9)$ & $(3,5,7)$ & $(5,7,9)$ & $(3,5,7)$ & $(3,5,7)$ & $(5,7,9)$ & $(5,7,9)$ & $(7,9,9)$ & $(5,7,9)$ \\
$\mathrm{A}_{4}$ & $(7,9,9)$ & $(5,7,9)$ & $(5,7,9)$ & $(5,7,9)$ & $(3,5,7)$ & $(5,7,9)$ & $(5,7,9)$ & $(1,3,5)$ & $(5,7,9)$ & $(5,7,9)$ \\
$\mathrm{A}_{5}$ & $(5,7,9)$ & $(5,7,9)$ & $(7,9,9)$ & $(5,7,9)$ & $(5,7,9)$ & $(5,7,9)$ & $(5,7,9)$ & $(3,5,7)$ & $(5,7,9)$ & $(3,5,7)$ \\
$\mathrm{W}$ & 0.219 & 0.018 & 0.17 & 0.035 & 0.152 & 0.124 & 0.061 & 0.095 & 0.051 & 0.075 \\
\hline
\end{tabular}

Following the rest of procedure to results of TOPSIS, the weighted decision matrix is calculated. By multiplication of each criteria weight to the related rating in decision matrix, Table 9 is obtained. Likewise, the normalized weighted fuzzy decision matrix is represented in Table 10. Then the fuzzy positive ideal solution (FPIS) and fuzzy negative ideal solution (FNIS) will be computed as shown in 
Table 11 and 12. In addition, the distances of each alternative from the FPIS and FNIS for the criteria $\mathrm{C}_{4}$ in front of alternative $\mathrm{A}_{5}$ includes 0.28 and 0.6 , respectively. The equations for these quantities are as follows;

$$
d_{v}\left(A_{1}, A^{*}\right)=\sqrt{\frac{1}{3}\left[(0.56-1)^{2}+(0.78-1)^{2}+(1-1)^{2}\right]}=0.28 \quad d_{v}\left(A_{1}, A^{-}\right)=\sqrt{\frac{1}{3}\left[(0.56-0.2)^{2}+(0.78-0.2)^{2}+(1-0.2)^{2}\right]}=0.6
$$

Table 9

Weighted fuzzy decision matrix

\begin{tabular}{ccccccccccc}
\hline & $\mathrm{C}_{1}$ & $\mathrm{C}_{2}$ & $\mathrm{C}_{3}$ & $\mathrm{C}_{4}$ & $\mathrm{C}_{5}$ & $\mathrm{C}_{6}$ & $\mathrm{C}_{7}$ & $\mathrm{C}_{8}$ & $\mathrm{C}_{9}$ & $\mathrm{C}_{10}$ \\
\hline $\mathrm{A}_{1}$ & $(1.1,1.5,1.9)$ & $(0.01,0.05,0.1)$ & $(0.9,1.2,1.5)$ & $(0.04,0.1,0.18)$ & $(0.8,1.1,1.4)$ & $(0.9,1.2,1.2)$ & $(0.2,0.3,0.5)$ & $(0.5,0.7,0.9)$ & $(0.3,0.4,0.5)$ & $(0.4,0.5,0.6)$ \\
$\mathrm{A}_{2}$ & $(1.1,1.5,1.9)$ & $(0.05,0.1,0.13)$ & $(0.9,1.2,1.5)$ & $(0.2,0.3,0.3)$ & $(0.8,1.1,1.4)$ & $(0.7,0.9,1.2)$ & $(0.3,0.4,0.6)$ & $(0.5,0.7,0.9)$ & $(0.3,0.4,0.5)$ & $(0.4,0.5,0.6)$ \\
$\mathrm{A}_{3}$ & $(0.6,1.1,1.5)$ & $(0.1,0.13,0.1)$ & $(0.5,0.9,1.2)$ & $(0.18,0.2,0.3)$ & $(0.5,0.8,1.1)$ & $(0.4,0.6,0.9)$ & $(0.3,0.45,0.6)$ & $(0.5,0.7,0.9)$ & $(0.4,0.5,0.5)$ & $(0.4,0.5,0.6)$ \\
$\mathrm{A}_{4}$ & $(1.5,1.9,1.9)$ & $(0.1,0.13,0.1)$ & $(0.9,1.2,1.5)$ & $(0.18,0.2,0.3)$ & $(0.5,0.8,1.1)$ & $(0.6,0.9,1.2)$ & $(0.3,0.5,0.6)$ & $(0.1,0.3,0.5)$ & $(0.3,0.4,0.5)$ & $(0.4,0.5,0.6)$ \\
$\mathrm{A}_{5}$ & $(1.1,1.5,1.9)$ & $(0.1,0.13,0.1)$ & $(1.2,1.5,1.5)$ & $(0.18,0.25,0.3)$ & $(0.8,1.1,1.4)$ & $(0.6,0.9,1.2)$ & $(0.3,0.5,0.6)$ & $(0.3,0.5,0.7)$ & $(0.3,0.4,0.5)$ & $(0.2,0.4,0.5)$ \\
\hline
\end{tabular}

Table 10

Normalized weighted fuzzy decision matrix for supplier evaluation

\begin{tabular}{cccccccccccccccc}
\hline & $\mathrm{C}_{1}$ & $\mathrm{C}_{2}$ & $\mathrm{C}_{3}$ & $\mathrm{C}_{4}$ & $\mathrm{C}_{5}$ & $\mathrm{C}_{6}$ & \multicolumn{2}{c}{$\mathrm{C}_{7}$} & $\mathrm{C}_{8}$ & $\mathrm{C}_{10}$ & \\
\hline $\mathrm{A}_{1}$ & $(0.6,0.8,1)$ & $(0.2,0.34,1)$ & $(0.56,0.78,1)$ & $(0.2,0.6,1)$ & $(0.56,0.78,1)$ & $(0.78,1,1)$ & $(0.43,0.7,1)$ & $(0.54,0.78,1)$ & $(0.56,0.78,1)$ & $(0.56,0.78,1)$ \\
$\mathrm{A}_{2}$ & $(0.6,0.8,1)$ & $(0.43,0.6,1)$ & $(0.56,0.78,1)$ & $(0.78,1,1)$ & $(0.56,0.78,1)$ & $(0.56,0.78,1)$ & $(0.55,0.78,1)$ & $(0.54,0.78,1)$ & $(0.56,0.78,1)$ & $(0.56,0.78,1)$ \\
$\mathrm{A}_{3}$ & $(0.43,0.72,1)$ & $(0.56,0.72,1)$ & $(0.43,0.72,1)$ & $(0.56,0.78,1)$ & $(0.43,0.72,1)$ & $(0.43,0.72,1)$ & $(0.55,0.78,1)$ & $(0.54,0.78,1)$ & $(0.78,1,1)$ & $(0.56,0.78,1)$ \\
$\mathrm{A}_{4}$ & $(0.78,1,1)$ & $(0.56,0.72,1)$ & $(0.56,0.78,1)$ & $(0.56,0.78,1)$ & $(0.43,0.72,1)$ & $(0.56,0.78,1)$ & $(0.55,0.78,1)$ & $(0.2,0.62,1)$ & $(0.56,0.78,1)$ & $(0.56,0.78,1)$ \\
$\mathrm{A}_{5}$ & $(0.6,0.8,1)$ & $(0.56,0.72,1)$ & $(0.78,1,1)$ & $(0.56,0.78,1)$ & $(0.56,0.78,1)$ & $(0.56,0.78,1)$ & $(0.55,0.78,1)$ & $(0.42,0.69,1)$ & $(0.56,0.78,1)$ & $(0.43,0.72,1)$ \\
\hline
\end{tabular}

Table 11

Fuzzy positive ideal solution

\begin{tabular}{cccccccccccc}
\hline$A^{+}$ & $\mathrm{C}_{1}$ & $\mathrm{C}_{2}$ & $\mathrm{C}_{3}$ & $\mathrm{C}_{4}$ & $\mathrm{C}_{5}$ & $\mathrm{C}_{6}$ & $\mathrm{C}_{7}$ & $\mathrm{C}_{8}$ & $\mathrm{C}_{9}$ & $\mathrm{C}_{10}$ \\
\hline $\mathrm{A}_{1}$ & 0.28 & 0.6 & 0.28 & 0.51 & 0.28 & 0.12 & 0.36 & 0.29 & 0.28 & 0.28 \\
$\mathrm{~A}_{2}$ & 0.28 & 0.4 & 0.28 & 0.12 & 0.28 & 0.28 & 0.28 & 0.29 & 0.28 & 0.28 \\
$\mathrm{~A}_{3}$ & 0.36 & 0.3 & 0.36 & 0.28 & 0.36 & 0.36 & 0.28 & 0.29 & 0.12 & 0.28 \\
$\mathrm{~A}_{4}$ & 0.12 & 0.3 & 0.28 & 0.28 & 0.36 & 0.28 & 0.28 & 0.51 & 0.28 & 0.28 \\
$\mathrm{~A}_{5}$ & 0.28 & 0.3 & 0.12 & 0.28 & 0.28 & 0.28 & 0.28 & 0.38 & 0.28 & 0.36 \\
\hline
\end{tabular}

Table 12

Fuzzy negative ideal solution

\begin{tabular}{cccccccccccc}
\hline$A^{-}$ & $\mathrm{C}_{1}$ & $\mathrm{C}_{2}$ & $\mathrm{C}_{3}$ & $\mathrm{C}_{4}$ & $\mathrm{C}_{5}$ & $\mathrm{C}_{6}$ & $\mathrm{C}_{7}$ & $\mathrm{C}_{8}$ & $\mathrm{C}_{9}$ & $\mathrm{C}_{10}$ \\
\hline $\mathrm{A}_{1}$ & 0.4 & 0.47 & 0.4 & 0.51 & 0.4 & 0.5 & 0.36 & 0.6 & 0.28 & 0.4 \\
$\mathrm{~A}_{2}$ & 0.4 & 0.53 & 0.4 & 0.73 & 0.4 & 0.4 & 0.42 & 0.6 & 0.28 & 0.4 \\
$\mathrm{~A}_{3}$ & 0.37 & 0.59 & 0.37 & 0.6 & 0.37 & 0.37 & 0.42 & 0.6 & 0.38 & 0.4 \\
$\mathrm{~A}_{4}$ & 0.5 & 0.59 & 0.4 & 0.6 & 0.37 & 0.4 & 0.42 & 0.52 & 0.28 & 0.4 \\
$\mathrm{~A}_{5}$ & 0.4 & 0.59 & 0.5 & 0.6 & 0.4 & 0.4 & 0.42 & 0.55 & 0.28 & 0.37 \\
\hline
\end{tabular}

The suppliers can be ranked according the results of the relative closeness to the ideal solution, where the suppliers have a larger value have the better rank among others. So, the process of supplier ranking goes on the computation of closeness coefficient for the five suppliers as the Table 13 explains;

Table 13

Closeness coefficient $\left(\mathrm{CC}_{\mathrm{i}}\right)$ and ranking of the five suppliers

\begin{tabular}{ccccccc}
\hline & $\mathrm{A}_{1}$ & $\mathrm{~A}_{2}$ & $\mathrm{~A}_{3}$ & $\mathrm{~A}_{4}$ & $\mathrm{~A}_{5}$ & Ranking \\
\hline$d_{i}^{-}$ & 3.28 & 2.77 & 2.99 & 2.97 & 2.84 & \\
$d_{i}^{*}$ & 4.32 & 4.56 & 4.47 & 4.48 & 4.59 & $\mathrm{~A}_{2}>\mathrm{A}_{5}>\mathrm{A}_{4}>\mathrm{A}_{3}>\mathrm{A}_{1}$ \\
$C C_{i}$ & 0.568 & 0.622 & 0.599 & 0.601 & 0.618 & \\
\hline
\end{tabular}


The results of ranking determine that the supplier $\mathrm{A}_{2}$ is the best among the other suppliers according the ten environmental criteria in a fuzzy environment. The arrangement of suppliers are $A_{2}>A_{5}>A_{4}>A_{3}$ $>A_{1}$. Hence, the results are shown the second supplier would be the best choice for management and the supplier number 5 and the rest of them are in the next places. It also needs to review any additional information about suppliers to make a final decision. Often decision teams attend in a consultant meeting and interpret their opinion directly.

\section{Conclusion}

The paper has represented a multi criteria decision making approach for supplier selection and assessment under fuzzy environment. The proposed framework utilizes three distinguished phases. In the first phase, paper has investigated supplier characteristics and criteria that need to be evaluated. Large numbers of related and academic studies have been reviewed and ultimately ten major criteria have been selected like price, green capacity, personnel training, quality, etc. The phase 2 has declared how the criteria were important for experts and in other words this phase tend to appear the relative importance of criteria and factors associated by decision making team. AHP fundamentally has been built to perceive the importance or relative weights of different activities in a decision making process. Finally, the third phase systematically prioritizes the degree of each supplier according the data by fuzzy TOPSIS model. For any future studies and investigations, it can be suggested to use different MCDM methods as DEMATEL, SAW, PROMETHEE and implementing more flexible factors to make comprehensive comparison attitude between suppliers. Another advice is to force the suppliers to collaborate and represent real data and information. In some cases, there would be huge number of suppliers that in these situations an initial performance assessment will be helpful to give more suitable suppliers and remove undesirable ones.

\section{References}

Amiri, M. P. (2010). Project selection for oil-fields development by using the AHP and fuzzy TOPSIS methods. Expert Systems with Applications, 37(9), 6218-6224.

Amy, H.I.L., Yan, K.H., Yu, L.C. (2011). Advances in mathematical and computatioal methods: addressing modern challenges of science, technology, and society. AIP Conference Proceedings, $1368,185-188$

Awasthi, A., Chauhan, S. S., \& Goyal, S. K. (2010). A fuzzy multi criteria approach for evaluating environmental performance of suppliers. International Journal of Production Economics, 126(2), 370-378.

Awasthi, A., Chauhan, S. S., \& Goyal, S. K. (2011). A multi-criteria decision making approach for location planning for urban distribution centers under uncertainty. Mathematical and Computer Modelling, 53(1), 98-109.

Badri, M. A. (2001). A combined AHP-GP model for quality control systems. International Journal of Production Economics, 72(1), 27-40.

Bala, A., Muñoz, P., Rieradevall, J., \& Ysern, P. (2008). Experiences with greening suppliers. The universitat autonoma de Barcelona. Journal of Cleaner Production, 16(15), 1610-1619.

Berrittella, M., Certa, A., Enea, M., \& Zito, P. (2007). An analytic hierarchy process for the evaluation of transport policies to reduce climate change impacts.

Buckley, J. J. (1985). Fuzzy hierarchical analysis. Fuzzy sets and systems, 17(3), 233-247.

Büyüközkan, G., \& Çifçi, G. (2012a). A novel hybrid MCDM approach based on fuzzy DEMATEL, fuzzy ANP and fuzzy TOPSIS to evaluate green suppliers. Expert Systems with Applications, 39(3), 3000-3011.

Büyüközkan, G., \& Çifçi, G. (2012b). Evaluation of the green supply chain management practices: a fuzzy ANP approach. Production Planning \& Control , 23(6), 405-418

Che, Z. H., Chiang, T. A., Tu, C., \& Chiang, C. J. (2010). A supplier selection model for product design changes. International Journal of Electronic Business Management, 8(1), 20-30. 
Chen, C. C., Tseng, M. L., Lin, Y. H., \& Lin, Z. S. (2010, December). Implementation of green supply chain management in uncertainty. In Industrial Engineering and Engineering Management (IEEM), 2010 IEEE International Conference on (pp. 260-264). IEEE.

Chen, C. T. (2000). Extensions of the TOPSIS for group decision-making under fuzzy environment. Fuzzy Sets and Systems, 114(1), 1-9.

Chiou, C. Y., Hsu, C. W., \& Hwang, W. Y. (2008, December). Comparative investigation on green supplier selection of the American, Japanese and Taiwanese electronics industry in China, Industrial Engineering and Engineering Management, 2008, IEEM 2008. IEEE International Conference on(pp. 1909-1914). IEEE.

Fazlollahtabar, H., Mahdavi, I., Ashoori, M. T., Kaviani, S., \& Mahdavi-Amiri, N. (2011). A multiobjective decision-making process of supplier selection and order allocation for multi-period scheduling in an electronic market. The International Journal of Advanced Manufacturing Technology, 52(9-12), 1039-1052.

Fu, H. P., \& Lin, S. W. (2009). Applying AHP to analyze criteria of performance measurement for national energy promotion projects. International Journal of Electronic Business, 7(1), 70-77.

Grisi, R. M., Guerra, L., \& Naviglio, G. (2010). Supplier performance evaluation for green supply chain management. In Business Performance Measurement and Management (pp. 149-163). Springer Berlin Heidelberg.

Grandzol, J. R. (2005). Improving the faculty selection process in higher education: A case for the analytic hierarchy process. IR Applications. Volume 6. Association for Institutional Research.

Humphreys, P., McCloskey, A., McIvor, R., Maguire, L., \& Glackin, C. (2006). Employing dynamic fuzzy membership functions to assess environmental performance in the supplier selection process. International Journal of Production Research, 44(12), 2379-2419.

Humphreys, P. K., Wong, Y. K., \& Chan, F. T. S. (2003). Integrating environmental criteria into the supplier selection process. Journal of Materials Processing Technology, 138(1), 349-356

Humphreys, P., McIvor, R., \& Chan, F. (2003). Using case-based reasoning to evaluate supplier environmental management performance. Expert Systems with Applications, 25(2), 141-153.

Hwang, C. L. \& Yoon, K. (1981). Multiple Attribute Decision Making: Methods and Applications. New york: Springer- Verlag.

Kannan, D., Khodaverdi, R., Olfat, L., Jafarian, A., \& Diabat, A. (2013). Integrated fuzzy multi criteria decision making method and multi-objective programming approach for supplier selection and order allocation in a green supply chain. Journal of Cleaner Production, 47, 355-367.

Kaufmann, A., Gupta, M. M., \& Kaufmann, A. (1985). Introduction to fuzzy arithmetic: theory and applications. New York: Van Nostrand Reinhold Company.

Khajej, M. (2010). Water conservation in Kuwait: a fuzzy analysis approach. Journal of Industrial Engineering International, 6(10), 90-105.

Khorramshahgol, R. (2012). An integrated strategic approach to supplier evaluation and selection. International Journal of Information Technology \& Decision Making, 11(01), 55-76.

Kuo, R. J., Wang, Y. C., \& Tien, F. C. (2010), Integration of artificial neural network and MADA methods for green supplier selection, Journal of Cleaner Production, 18(12), 1161-1170.

Kutlu, A. C., \& Ekmekçioğlu, M. (2012). Fuzzy failure modes and effects analysis by using fuzzy TOPSIS-based fuzzy AHP. Expert Systems with Applications, 39(1), 61-67.

Lee, A. H., Kang, H. Y., Hsu, C. F., \& Hung, H. C. (2009). A green supplier selection model for hightech industry. Expert systems with applications, 36(4), 7917-7927.

Li, X., \& Zhao, C. (2009, October), Selection of suppliers of vehicle components based on green supply chain, In Industrial Engineering and Engineering Management, 2009. IE\&EM'09. 16th International Conference on (pp. 1588-1591). IEEE.

Meziani, A. S., \& Rezvani, F. (1990). Using the analytical hierarchy process to select a financing instrument for a foreign investment. Mathematical and Computer Modelling, 13(7), 77-82.

Noci, G. (1997). Designing 'green' vendor rating systems for the assessment of a supplier's environmental performance. European Journal of Purchasing \& Supply Management, 3(2), 103114. 
Peng, J. (2012). Research on the optimization of green suppliers based on AHP and GRA, Journal of Information and Computational Science, 9(1), 173-182

Razmi, J., Songhori, M. J., \& Khakbaz, M. H. (2009). An integrated fuzzy group decision making/fuzzy linear programming (FGDMLP) framework for supplier evaluation and order allocation. The International Journal of Advanced Manufacturing Technology, 43(5-6), 590-607.

Saaty, T. (1980). The analytic hierarchy process. New york: Mc Grae-Hill .

Songhori, M. J., Tavana, M., Azadeh, A., \& Khakbaz, M. H. (2011). A supplier selection and order allocation model with multiple transportation alternatives. The International Journal of Advanced Manufacturing Technology, 52(1-4), 365-376.

Thongchattu, C., \& Siripokapirom, S. (2010, August). Green supplier selection consensus by neural network. In Mechanical and Electronics Engineering (ICMEE), $20102^{\text {nd }}$ International Conference on (Vol. 2, pp. V2-313). IEEE.

Tuzkaya, G., Ozgen, A., Ozgen, D., \& Tuzkaya, U. R. (2009). Environmental performance evaluation of suppliers: A hybrid fuzzy multi-criteria decision approach. International Journal of Environmental Science \& Technology, 6(3), 477-490.

Wang, J. W., Cheng, C. H., \& Huang, K. C. (2009). Fuzzy hierarchical TOPSIS for supplier selection. Applied Soft Computing, 9(1), 377-386.

Wen, U. P., \& Chi, J. M. (2010,). Developing green supplier selection procedure: A DEA approach. In Industrial Engineering and Engineering Management (IE\&EM), 2010 IEEE 17Th International Conference on (pp. 70-74). IEEE.

Wisner, j. D.-c.-k. (2012). Principles of supply chain management. Ohio - USA: South western Cengage learning .

Wong, T. N., Lee, L. H., \& Sun, Z. (2012). CSR and environmental criteria in supplier selection. In Proc Asia Pac Ind Eng Manag Syst Conf.

Wu, H. Y., Chen, J. K., Chen, I., \& Zhuo, H. H. (2012), Ranking universities based on performance evaluation by a hybrid MCDM model. Measurement, 45(5), 856-880.

Yan, G. E. (2009, May). Research on Green Suppliers' Evaluation Based on AHP \& Genetic Algorithm, In 2009 International Conference on Signal Processing Systems (pp. 615-619), IEEE

Yang, T., \& Hung, C. C. (2007). Multiple-attribute decision making methods for plant layout design problem. Robotics and computer-integrated manufacturing,23(1), 126-137.

Yang, Y. Z., \& Wu, L. Y. (2008, October). Extension method for green supplier selection. In Wireless Communications, Networking and Mobile Computing, 2008. WiCOM'08. 4th International Conference on (pp. 1-4). IEEE.

Yu, X., Guo, S., Guo, J., \& Huang, X. (2011). Rank B2C e-commerce websites in e-alliance based on AHP and fuzzy TOPSIS. Expert Systems with Applications, 38(4), 3550-3557.

Zadeh, L. A. (1965). Fuzzy sets. Information and Control, 338-353 .

Zhang, H. C., Li, J., \& Merchant, M. E. (2003). Using fuzzy multi-agent decision-making in environmentally conscious supplier management, CIRP Annals-Manufacturing Technology, 52(1), 385-388.

Zimmermann, H. J. (1992). Fuzzy Set Theory and Its Applications Second, Revised Edition. Kluwer academic publishers 